\title{
La división político administrativa en Cuba: antecedentes y actualidad
}

\author{
The political administrative division in Cuba:background and current
}

\author{
C. Elier Méndez Delgado*, María del Carmen Lloret Feijóo*
}

\begin{abstract}
Resumen: En este trabajo se explican las diferentes divisiones territoriales por las que ha atravesado la Isla de Cuba desde su origen hasta nuestros días. En Cuba se aprecian cambios regionales significativos en el transcurso de los últimos cuatro siglos y desde el año 1600 se comenzaron a realizar estudios dirigidos a conformar la División Político Administrativa; después de varios años, ya desde el 8 de octubre de 1607 la Isla quedó dividida en "dos mitades" con gobiernos independientes uno del otro: La Habana y Santiago de Cuba, reservándose al gobernador de La Habana el título de Capitán General. Hasta entonces la Isla de Cuba fue considerada como una sola provincia; esta disposición se recoge en la historia de Cuba, como la primera segmentación territorial emprendida por la metrópolis, pero no fue ejecutada hasta 1774, a consecuencia de un crecimiento demográfico, con una población de aproximadamente 171620 habitantes, y un desarrollo económico considerable, basado en la economía de plantación y el despegue de la industria azucarera. En la actualidad, después de 7 Divisiones Políticas Administrativas, la Isla de Cuba tiene 15 provincias y un municipio especial llamado "La isla de la juventud" que se ubica al sur occidental de Cuba. Estas transformaciones y Divisiones Territoriales quedan explicada y argumentada de forma diáfana en este trabajo.
\end{abstract}

Palabras clave: Regiones, Territorios, División Político Administrativa, Desarrollo Territorial, Antecedente Regionales, División Político Administrativa en Cuba.

\begin{abstract}
This work explains the different territorial divisions through which the Island of Cuba has passed from its origin to the present. Important regional changes are taking place in Cuba in the course of the last four centuries and since 1600 studies have been carried out aimed at forming the Political-Administrative Division; After several years, from October 8, 1607, the island was divided into "two halves" with governments independent from each other: Havana and Santiago de Cuba, reserving the title of Captain General for the governor of Havana. Until then, the Island of Cuba was considered as a single province; This provision is included in the history of Cuba, as the first territorial segmentation undertaken by the metropolis, but it was not implemented until 1774, as a result of demographic growth, with a population of approximately 171,620 inhabitants, and considerable economic development, based on the plantation economy and the take-off of the sugar industry. At present, after 7 Administrative Political Divisions, the Island of Cuba has 15 provinces and a special municipality called "La Isla de la Juventud" which is located
\end{abstract}

\footnotetext{
* Dr. Profesor Titular Departamento de Economía, Facultad de Ciencias Económicas. Universidad Central "Marta Abreu" de Las Villas, Cuba, ejmendez@uclv.edu.cu https://orcid.org/0000-0002-1050-2843

** Ms. Profesora Auxiliar Departamento de Economía. Facultad de Ciencias Económicas. mlloret@uclv.edu.cu https://orcid.org/0000-0002-3051-0648
} 
in the southwestern part of Cuba. These transformations and territorial divisions are clearly explained and argued in this work.

Keywords: Regions, Territories, Administrative Political Division, Territorial Development, Regional Background, Administrative Political Division in Cuba.

Recibido: 22 enero 2021 Aceptado: 5 mayo 2021

\section{Introducción}

La División Político Administra (DPA) de un país puede ser cambiante en el tiempo y ajustarse al desarrollo que va teniendo, hay factores formadores de regiones, que facilitan el mejor desempeño territorial y local, tendientes a equilibrar las regiones y zonas, para facilitar el aprovechamiento al máximo los recursos endógenos y posibilitar un desarrollo armónico; en el caso de Cuba se aprecian cambios regionales significativos en el transcurso de los últimos cuatro siglos.

En 1510 fue creada la Gobernación de Cuba dentro del Virreinato de la Nueva España, dependiente de la Real Audiencia de Santo Domingo, con capital en Santiago de Cuba y se fundan las 7 primeras villas en la Isla de Cuba: Baracoa, Bayamo, Santiago de Cuba, Puerto Príncipe, Trinidad, Sancti Spiritus y San Cristóbal de La Habana.

Alrededor del 1560, cuando la población aborigen de la Isla se estimó en 200000 habitantes, el Padre Bartolomé de las Casas concibió más de una veintena de regiones; estas fueron conocidas como Maisí, Bany, Sagua, Maniabón, Barajagua, Bayamo, Mayné, Guaynaga, Bayaquitirí, Macaca, Boyuca, Cueiba, Cayaguayo, Guaymaro, Camagüey, Ornofay, Cubanacán, Guamuhaya, Mangón, Jagua, Sabaneque, Habanana, Marién, Guaniguanico y Guanahacabibes. Estas fueron las primeras regiones que se conocieron en Cuba y desde entonces, hasta el año 2021 se han dado transformaciones significativas, tal como se podrá apreciar en el desarrollo de este trabajo.

El objetivo de este trabajo es explicar, ordenar y sistematizar los aspectos que a juicio de los autores caracterizan desde los aborígenes hasta el presente las diferentes divisiones territoriales por las que ha transitado la Isla de Cuba.

\section{Desarrollo}

Desde el año 1600 en Cuba se comenzaron a realizar estudios dirigidos a conformar la DPA, y después de varios años, el 8 de octubre de 1607 mediante la real cédula expedida por el rey Felipe III, la Isla quedó dividida en "dos mitades" con gobiernos independientes uno del otro: La Habana y Santiago de Cuba, reservándose al gobernador de La Habana el título de Capitán General. Hasta entonces la Isla de Cuba fue considerada como una sola provincia; esta disposición se recoge en la historia de Cuba, como la primera segmentación territorial emprendida por la metrópolis, pero no fue ejecutada hasta 1774, a consecuencia de un crecimiento demográfico, con una población de aproximadamente 171620 habitantes, y un desarrollo económico considerable, basado en la economía de plantación y el despegue de la industria azucarera. 
Mapa No.1.

1ra. DPA en 1774

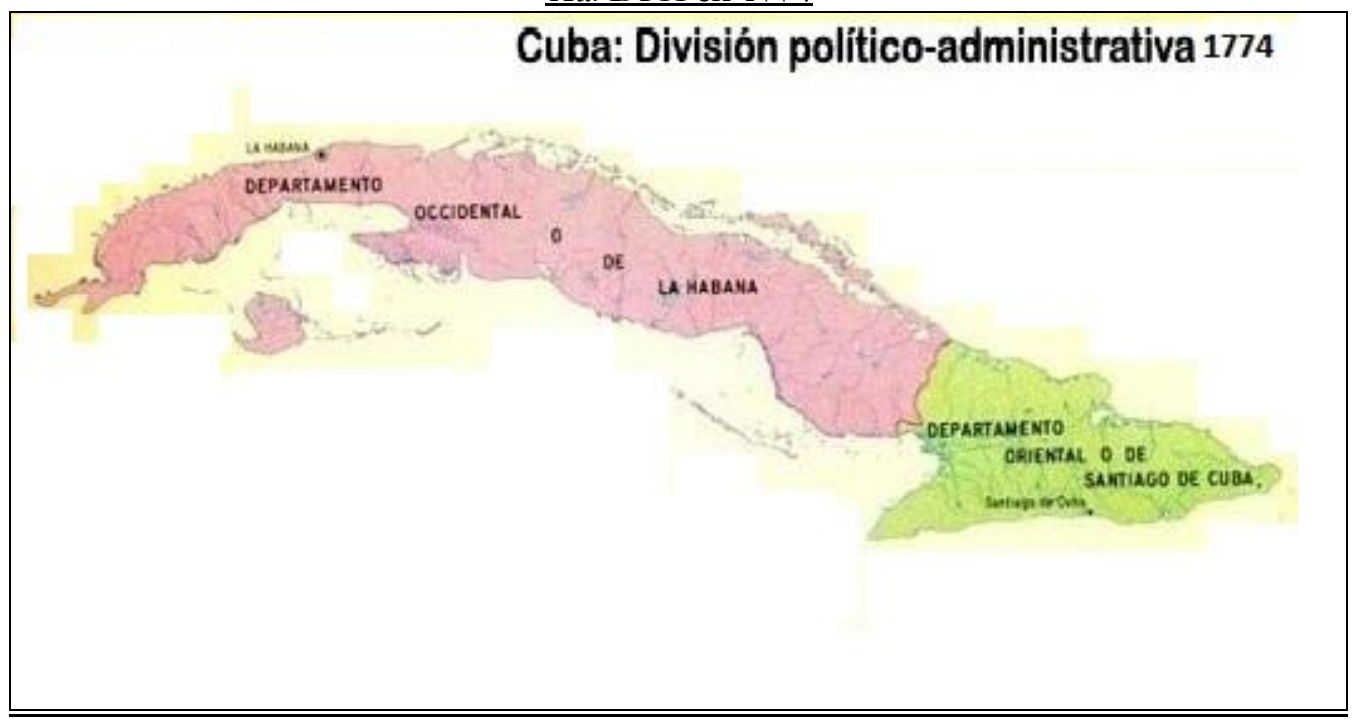

En el Mapa No.1 se aprecia que la isla comprendía solo dos departamentos: el Oriental o de Santiago de Cuba, con sede en esa ciudad (en el territorio que hoy ocupan las cinco provincias orientales) y el Occidental o de La Habana (desde las actuales provincias de Pinar del Río hasta Camagüey), incluida la entonces Isla de Pinos, con cabecera en la Villa de San Cristóbal de La Habana, convertida en capital floreciente.

La evolución histórica de DPA denota una estrecha relación con la demografía; pues en la medida en que el país ha crecido en población se han tenido que ajustar las estructuras territoriales de la época. Otras dos divisiones tuvieron lugar durante el siglo XIX. La primera, después de 53 años, en 1827 los departamentos se convirtieron en tres: el Oriental que conservó básicamente la misma superficie, mientras el Occidental abarcaba la geografía comprendida hoy de Pinar del Río a Matanzas, más la Isla de Pinos.

Mapa No.2.

2da. DPA en 1827, después de 53 años.

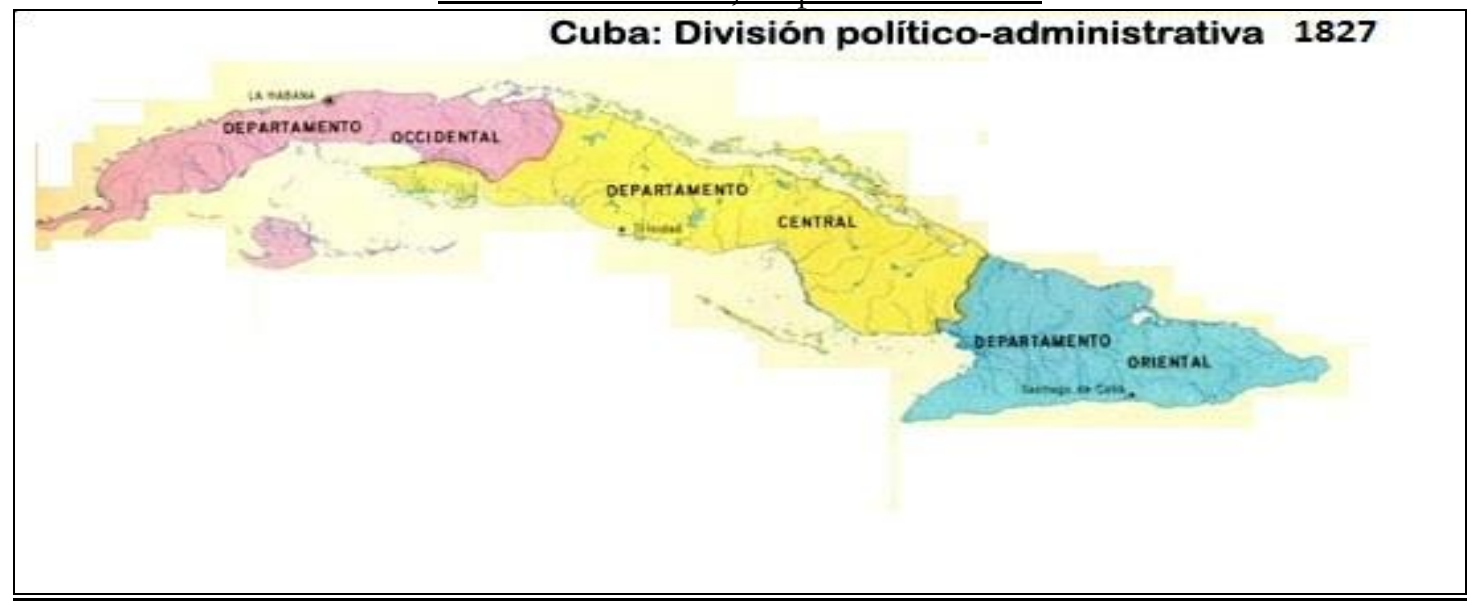


Departamento Central fue el nombre de la Región que contemplaba el área de los actuales territorios de una parte de la actual provincia de Las Tunas, la actual provincia de Camagüey, Ciego de Ávila, Sancti Spíritus, Villa Clara y Cienfuegos; incluso ocupaba una parte importante de la actual provincia de Matanzas, lo que es hoy el municipio de la Ciénaga de Zapata, como se puede ver en el Mapa No.2. La capital de este Departamento Central en ese momento merecía ser Trinidad, pues era la ciudad donde se localizaba un importante núcleo poblacional y tenía el desarrollo azucarero encabezado por el Valle de los Ingenios; curiosamente en estos años Trinidad llegó a identificarse más con Cartagena de India en Colombia, que con la Ciudad de Sancti Spíritus que estaba muy cerca geográficamente de Trinidad. Ya a mediados de la centuria, los habitantes de Cuba sobrepasaban el millón. La denominación de provincias aparece por vez primera en 1878, cuando por el Real Decreto del 9 de junio de ese año, se dicta la creación de áreas determinadas para ese fin.

Mapa No.3.

3ra. DPA en 1878, después de 51 años

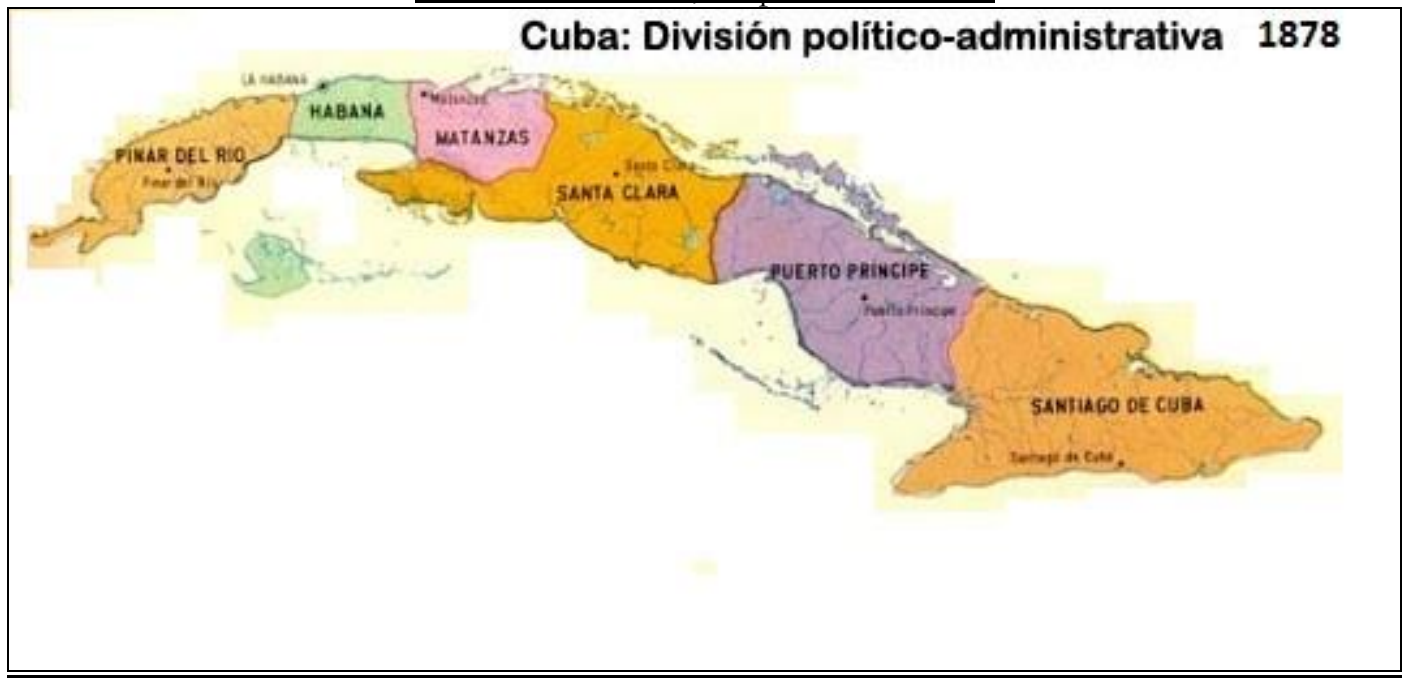

Las razones políticas, más que las geográficas y demográficas fueron las que motivaron a la metrópolis a dividir la Isla en seis porciones. Una vez concluida la Guerra de los Diez Años y escenificada la Protesta de Baraguá, el gobierno español se vio precisado a ofrecer determinadas concesiones (las cuales nunca cumplió) a los insurrectos cubanos, entre ellas la de tener representación en las Cortes españolas. Ello explica la división por provincias a fin de elegir diputados por cada una de ellas: Santiago de Cuba, Puerto Príncipe, Santa Clara, Matanzas, La Habana y Pinar del Río, con sedes principales en las ciudades de igual nombre, fueron las jurisdicciones establecidas en Cuba. La Isla de Pinos perteneció entonces a la provincia de La Habana.

El aumento de la natalidad en la Isla de Cuba y las migraciones europeas al país, luego de la Segunda Guerra Mundial, motivaron que la población creciera hasta alrededor de los 5829029 habitantes en 1953, fecha en que tuvo lugar una nueva DPA. 


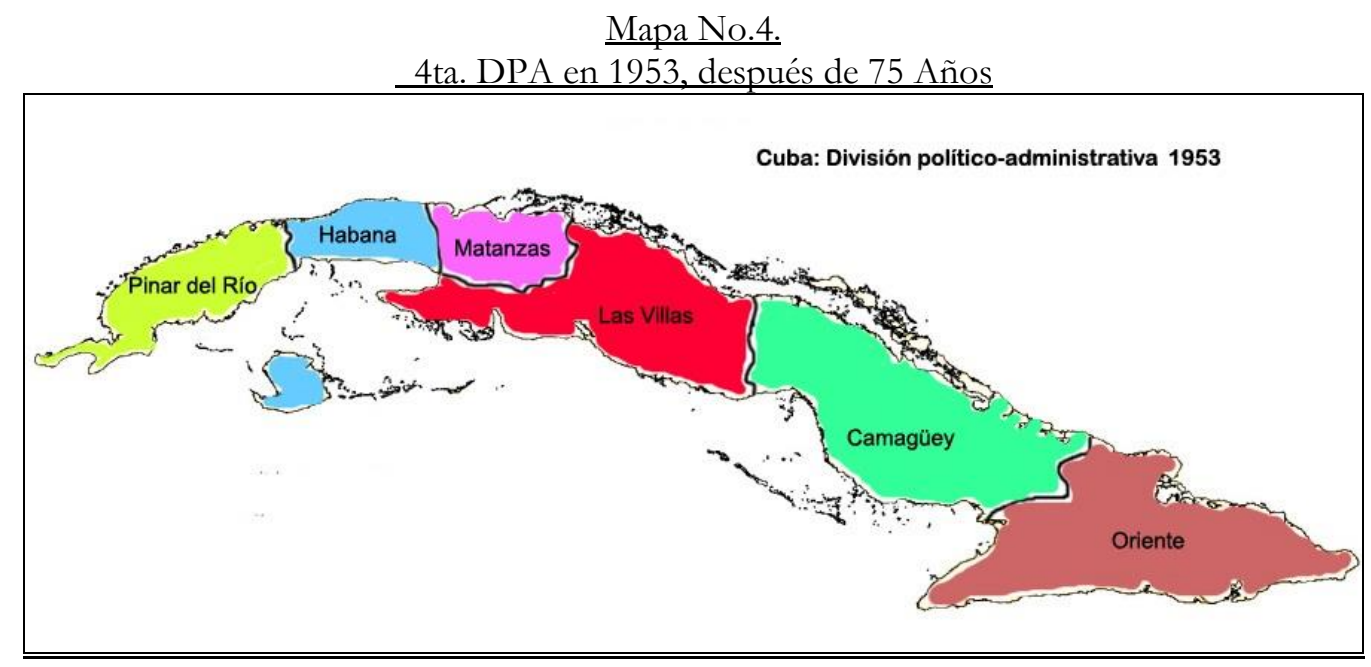

En esta oportunidad se mantuvieron aproximadamente los límites territoriales, pero cambiaron los nombres de algunas provincias. Santa Clara pasó a llamarse Las Villas; Puerto Príncipe, se le llamó Camagüey, mientras Santiago de Cuba se nombró Oriente.

El incipiente desarrollo municipal en Cuba tuvo su origen en las grandes deformaciones y desigualdades socioeconómicas previas al triunfo de la revolución en enero de 1959 y por tanto, parte de la necesidad impostergable de encaminar los esfuerzos hacia el ordenamiento de los territorios en aras del desarrollo demandado por el proceso revolucionario en auge. Los orígenes y rasgos del diseño territorial y local en la isla se remontan al pasado colonial y se extienden al período republicano previo al triunfo revolucionario; con la Constitución de 1901 se dan los primeros pasos relacionados con las estructuras y poderes locales; más tarde, en la Constitución de 1940, entonces una de las más avanzadas del continente, se asentó la necesidad de fortalecer la actividad de las localidades o municipios. A mediados de siglo XX Cuba contaba con 126 municipios distribuidos irregularmente en las seis provincias, por ejemplo, 26 en La Habana, contra sólo nueve en Camagüey.

Desde los primeros años del triunfo revolucionario se incorporó la región como un estabón intermedio entre la provincia y el municipio. Mas ese elemento provocó cierto distanciamiento en la ejecución de acciones de la Dirección nacional y la base, y fue suprimido en el contexto de creación de las 14 provincias y los 169 municipios, en 1976.

En 1970 hay otra DPA, la que mantuvo las seis provincias, con los nombres determinados en 1953, pero con ajustes territoriales en los límites de algunas. La Habana tomó de Pinar del Río los municipios de Mariel, Artemisa y Guanajay; Las Villas cedió a Matanzas la Ciénaga de Zapata, y Oriente creció sobre Camagüey en las áreas que ocupan los municipios de Amancio Rodríguez, y Colombia.

Como un paso significativo en la institucionalización del país, luego de más de 15 años de aplicación de experiencias, la Revolución cubana acomete la renovación total de las legislaciones heredadas de la etapa colonial. El Partido y el Gobierno Revolucionario consideraron factible la creación de nuevas formas del Poder Popular. En uno de los "Por cuantos", la Ley 1269 del 3 de mayo de 1974 plantea "... instituir la elección de los Órganos del Poder Popular, de modo que las masas queden incorporadas institucionalmente a la dirección estatal y administrativa y que el pueblo forme parte directa de los órganos del Estado, plenamente identificado con este como Estado Socialista de los trabajadores, profundamente democrático... ". 
Mapa No.5.

5ta. DPA en 1970, después de 17 años.

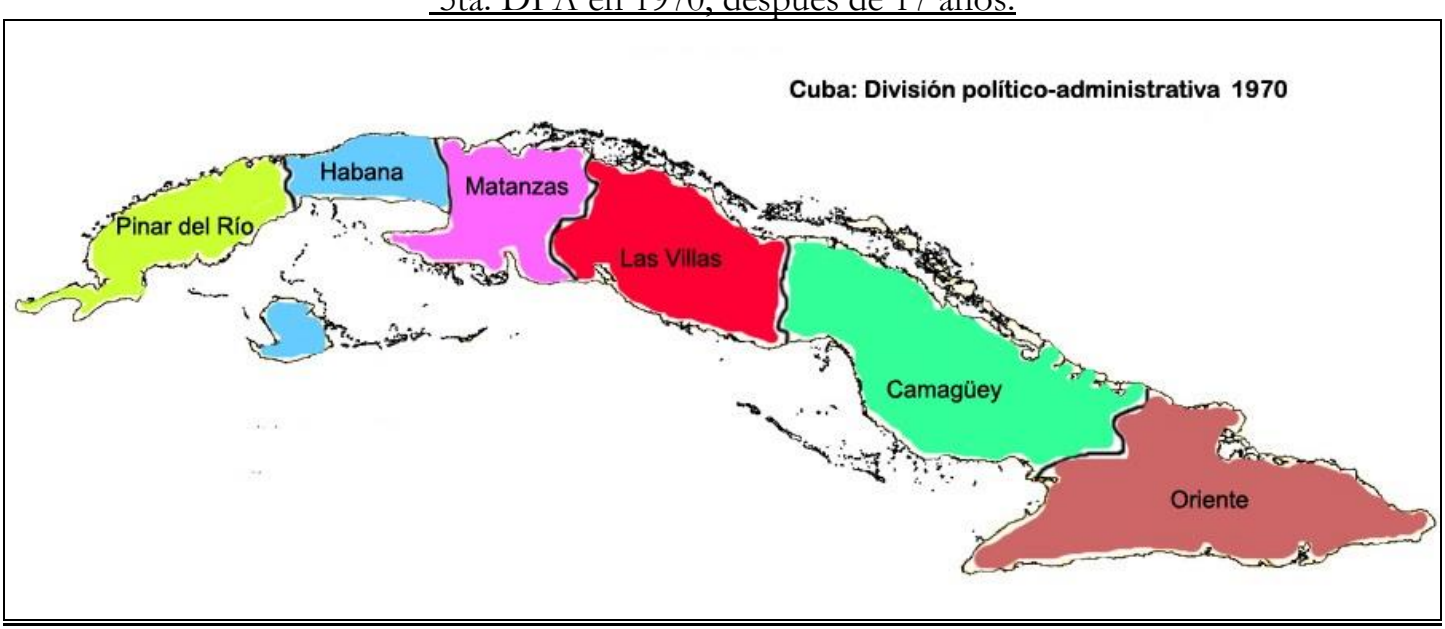

Una resolución del Primer Congreso del Partido Comunista de Cuba, en diciembre de 1975 indicó la aplicación de una nueva DPA del país, con la finalidad de lograr una vinculación más directa entre la dirección nacional y la base, en correspondencia con las exigencias de nuestro desarrollo económico y social planificado.

$\mathrm{Al}$ año siguiente el número de provincias aumentó a 14 y se decidió la figura del Municipio Especial Isla de Pinos, que a partir de 1978 recibió el nombre de Isla de la Juventud. Ese territorio pasó a ser atendido directamente por el nivel central.

Mapa No.6.

6ta. DPA en 1976, después de 6 años

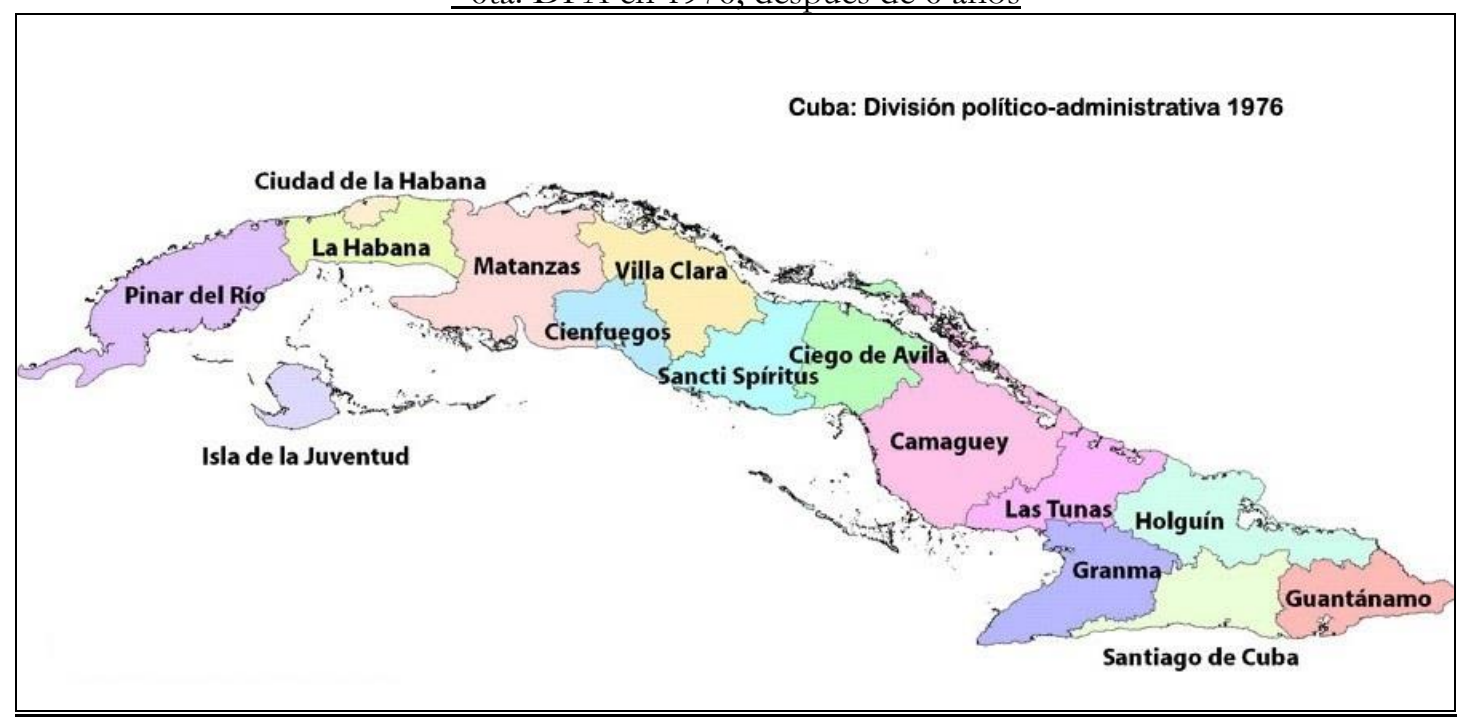

Esta DPA multiplicó la antigua provincia de Oriente por cinco: Guantánamo, Santiago de Cuba, Granma, Holguín y Las Tunas. Camagüey cedió parte de su superficie a la nueva provincia de Ciego de Ávila. La provincia de Las Villas pasó a llamarse Villa Clara y disminuyó su territorio en favor de la 


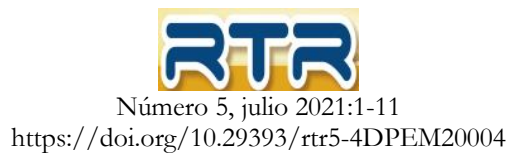

creación de las provincias de Cienfuegos y Sancti Spíritus. La provincia de La Habana se convirtió en dos: Ciudad de La Habana, donde se localiza la capital del país, La Habana, y la inmensa provincia de La Habana (19 municipios) con la peculiaridad de no contar con una ciudad cabecera.

El territorio nacional quedó conformado, según esta DPA en 14 provincias y 169 municipios, incluyendo el municipio especial Isla de la Juventud. La capital del país es La Habana. Las 14 provincias son: Pinar del Río, Ciudad de La Habana, La Habana, Matanzas, Villa Clara, Cienfuegos, Sancti Spíritus, Ciego de Ávila, Camagüey, Las Tunas, Holguín, Granma, Santiago de Cuba y Guantánamo. La mayor parte de las capitales de provincia tienen el mismo nombre de éstas.

Las ciudades más importantes con esa DPA son: La Habana (capital del país y de las provincias de Ciudad de La Habana y La Habana), Pinar del Río (capital de provincia), Matanzas (capital de provincia), Santa Clara (capital de la provincia de Villa Clara), Cienfuegos (capital de provincia), Sancti Spíritus (capital de provincia), Trinidad (ciudad cabecera del municipio de igual nombre, provincia de Sancti Spíritus), Ciego de Ávila (capital de provincia), Camagüey (capital de provincia), Las Tunas (capital de provincia), Holguín (capital de provincia), Manzanillo (ciudad cabecera del municipio de igual nombre, provincia de Granma), Bayamo (capital de la provincia Granma), Santiago de Cuba (capital de provincia), Guantánamo (capital de provincia), Baracoa (ciudad cabecera del municipio de igual nombre, provincia de Guantánamo), y Nueva Gerona (capital del municipio especial Isla de la Juventud).

\section{La división política administrativa del 2011}

La DPA más reciente, que entró en vigor con el inicio del año 2011, pretendió una organización más racional a favor de los servicios a la población, y mayor funcionalidad para las labores de los gobiernos y las administraciones. Además entre otros objetivos pretendió la reducción de plantillas y locales, a partir de la ubicación de organizaciones políticas y de masas, y entidades del Poder Popular en una misma edificación; se pretende entre otros aspectos hacer mas racionalidad el número de cuadros de dirección aprobados en los niveles e instituciones de las nuevas provincias de Artemisa y Mayabeque, pues ahora solo constituyen el $50 \%$ de la cantidad que se desempeñaba en la entonces provincia de La Habana.

Además la modificación planteada para las provincias occidentales (Pinar del Río, Artemisa y Mayabeque) ofrece coherencia desde el punto de vista del número de municipios (11 cada una), lo cual reduce la distancia entre los municipios y la cabecera provincial; el contar con una capital territorial favorece a la identidad y el fortalecimiento del sentido de pertenencia. 
Mapa No.7. 7ma. DPA en 2011, después de 35 años (Nuevas provincias de Artemisas y Mayabeque).

\section{Cuba tiene dos nuevas provincias ARTEMISA Y MAYABEQUE}
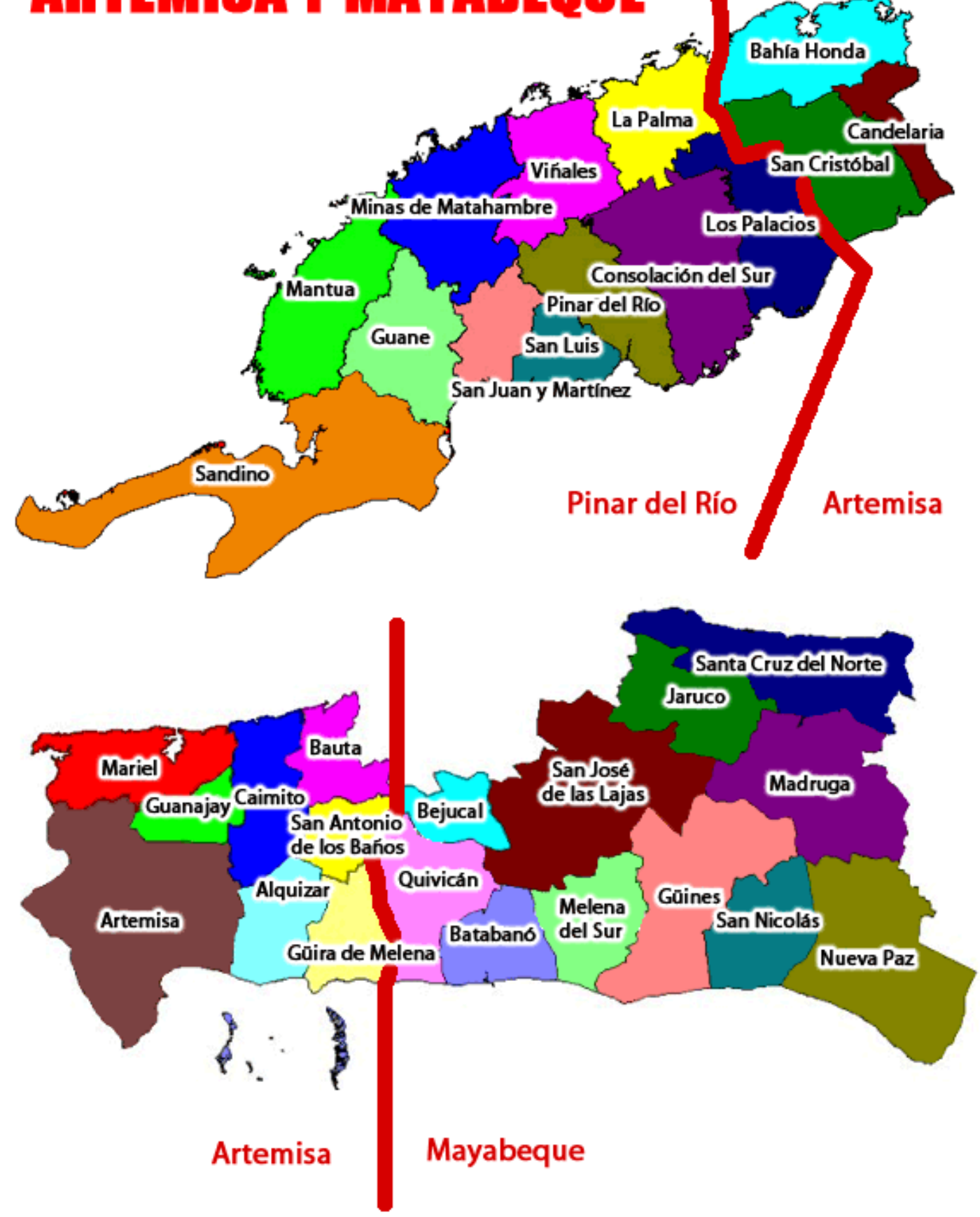
La nueva provincia de Artemisa recibe tres municipios pinareños: Bahía Honda, San Cristóbal y Candelaria y tiene su capital en el municipio de igual nombre, mientras Mayabeque asume como cabecera y Capital a San José de las Lajas. De esta manera se pone fin a la dependencia que durante 35 años de existencia tuvo la provincia de La Habana de localizar su centro en la capital del país y no en territorio propio.

El perímetro de lo que desde 1976 fue Ciudad de La Habana recupera su nombre histórico: La Habana, demarcación que recibe porciones de tierra alrededor de la Escuela Latinoamericana de Medicina, la Universidad de las Ciencias Informáticas, el lado este de la meseta de El Cacahual, y asentamientos poblacionales Tirabeque 1 y 2 , hasta ahora pertenecientes a Bejucal.

Varadero deja de ser municipio para integrarse al de Cárdenas como era antes de la DPA de 1976. La península de Hicacos, más el área existente hasta el hotel Oasis, se constituye en zona de administración especial subordinada al Consejo de Ministros. Con esta modificación, al salir Varadero de la relación de los municipios del país, se reduce en uno el número de estos y en total son 168 los municipios el país.

La más oriental de las provincias solo ajusta sus límites entre los municipios de Guantánamo, Manuel Tames y Yateras como podrá apreciase en los mapas que aparecen seguidamente donde explican detalladamente las provincias que sufren transformación en sus límites geográficos.

Mapa No.8.

$7 \mathrm{ma}$. DPA en 2011, después de 35 años

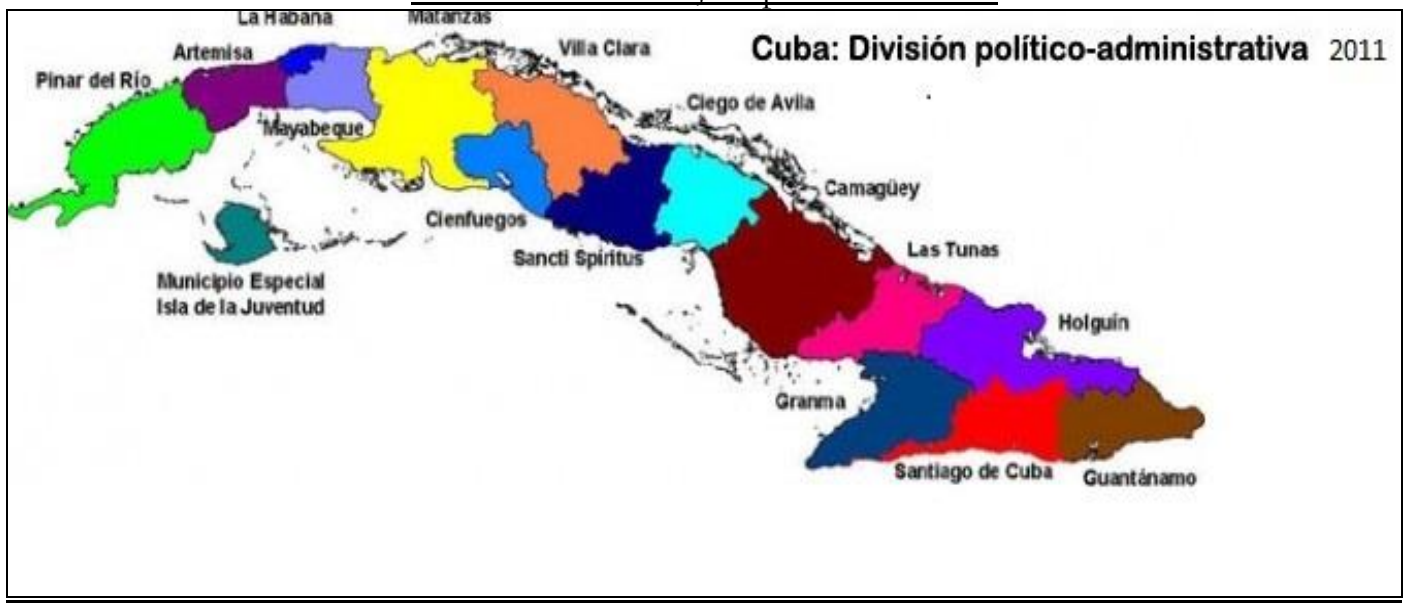

Al tratarse de un proyecto que modificó la Ley 1304 de julio de 1976, se sometió a la consideración de los diputados y se aprobó en un Periodo Ordinario de sesiones de la Asamblea Nacional del Poder Popular.

La Ciudad de La Habana recibió de la anterior provincia de La Habana la franja costera desde el río Santa Ana hasta el borde oeste de la Escuela Latinoamericana de Medicina (ELAM) y el área de autoabastecimiento de la Universidad de Ciencias Informáticas (UCI). Además, la capital adicionó el lado este de la Meseta del Cacahual, antes perteneciente al municipio de Bejucal, donde se encontraba en centro de Centro Nacional conocido por CENPALAB, y los asentamientos poblacionales de Tirabeque 1 y 2 . En total la capital asumió $5,75 \mathrm{~km}$ cuadrados nuevos. 
Generalidades sobre el nuevo codificador de la DPA que comenzó a regir a partir de enero del 2010.

El Codificador de la División Político-Administrativa (CoDPA) puesto en vigor mediante la resolución 129/2010 el 25 de Octubre de 2010, se conformó como instrumento de trabajo para la codificación de las unidades político administrativas en que se dividió el territorio nacional, de forma tal, que permitió la uniformidad en el procesamiento de las estadísticas continuas, las encuestas y los censos incluidos en el Sistema Estadístico Nacional; cuya rectoría metodológica corresponde a la Oficina Nacional de Estadística e Información (ONEI), así como para otros requerimientos que necesitan ubicación geográfica. A los efectos de este Nuevo Codificador se entenderá por territorio a las 15 provincias más el municipio especial de la Isla de la Juventud, definiéndose un total de 16 territorios a nivel nacional.

Para la codificación se mantiene la clave numérica confeccionada sobre la base de los principios del Sistema Decimal, componiéndose esta por 4 dígitos numéricos, los dos primeros de izquierda a derecha identifican la provincia y los dos últimos identifican al municipio.

La determinación de la clave numérica se ha hecho conservando el principio cartográfico establecido para la localización: de oeste a este y de norte a sur, tratándose de obtener la línea de continuidad más aproximada posible al derrotero.

Con vistas a mantener la comparabilidad de la información estadística con el menor margen de error, la ONEI ha considerado que es conveniente comenzar la nueva codificación por el número 21 para la provincia de Pinar del Río, 22 para la nueva provincia de Artemisa, 23 para La Habana, 24 para Mayabeque y así sucesivamente hasta Guantánamo con el 35. De igual forma se cambia la codificación del municipio especial Isla de la Juventud de 99.01 a 40.01, en el entendido que el 99, en el lenguaje de clasificadores, se reserva para cuando la información es desconocida.

Para facilitar el trabajo de adaptación, la ONEI ha elaborado un correlacionador con ambas codificaciones de la DPA, que permitirá adecuar la información de años anteriores para hacerlas comparables y estén disponibles para las publicaciones e investigaciones futuras que se realicen. Los interesados pueden informarse con más detalle en el sitio de la ONEI en http://www.onei.gob.cu/ en el acápite de Registros y Clasificadores. http://www.onei.gob.cu/node/14086

\section{Conclusiones}

Las diferentes Divisiones Político Administrativas por las que ha transitado la isla de Cuba, es resultado del desarrollo socioeconómico y demográfico que ha tenido el país desde sus orígenes hasta la actualidad. Las Divisiones Político Administrativas de la isla de Cuba han facilitado la organización, planificación y control de toda la actividades de dirección económica, territorial y local.

Cuba cuenta con un Codificador de la División Político-Administrativa (CoDPA), teniendo en cuenta los cambios aprobados por la Asamblea Nacional del Poder Popular en la sesión del $1^{\circ}$ de Agosto de 2010, en la cual se aprobó la Ley No. 110 "Modificativa de la Ley No. 1304 de 3 de Julio de 1976 de la División Político Administrativa" de la República de Cuba. El CoDPA tiene como objetivo, servir de instrumento de trabajo para la codificación de una forma uniforme, de las provincias y municipios en que se divide el territorio nacional, para todos aquellos trabajos e investigaciones en que se requiera ubicación geográfica. 


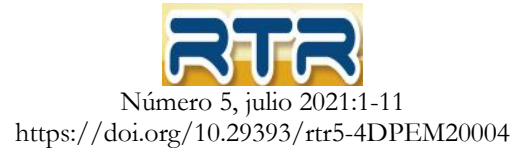

\section{Bibliografía}

- Alfredo Mateo Domingo. Historia de la división político-administrativa (1607-1976).

- Atlas demográfico de Cuba, 1979.

- Consultas a la Oficina Nacional de Estadísticas e Información de Cuba.

- http://www.onei.gob.cu/

- http://www.onei.gob.cu/node/14086

- http://www.juventudrebelde.cu/cuba/2010-08-01/cuba-con-nueva-division-politicoadministrativa/

- http://www.radiorebelde.cu/noticia/publica-gaceta-oficial-nueva-ley-division-politicoadministrativa-cuba-20100916/

- $\quad$ http://www.ecured.cu/index.php/Organizaci $\% \mathrm{C} 3 \% \mathrm{~B} 3 \mathrm{n}$ pol $\% \mathrm{C} 3 \% \mathrm{AD}$ ticoadministrativa de Cuba

- $\underline{\text { http://www.bedincuba.com/cuba/cuba informacion geografia division politico administrati }}$ va.htm

- http://www.cubaportal.org/paginas/conocercuba.aspx?id=304

- http://verbiclara.wordpress.com/2011/01/04/cuba-inicio-el-2011-con-nueva-divisionpolitico-administrativa/

- http://www.one.cu/ryc dpa.htm

- https://es.wikipedia.org/wiki/Historia territorial de Cuba 